\title{
Ideal Length of Thread Forms for Screws Used in Screw Fixation of Nondisplaced Femoral Neck Fractures
}

\section{Citation}

Liu, Christina. 2019. Ideal Length of Thread Forms for Screws Used in Screw Fixation of Nondisplaced Femoral Neck Fractures. Doctoral dissertation, Harvard Medical School.

\section{Permanent link}

http://nrs.harvard.edu/urn-3:HUL.InstRepos:41971519

\section{Terms of Use}

This article was downloaded from Harvard University's DASH repository, and is made available under the terms and conditions applicable to Other Posted Material, as set forth at http:// nrs.harvard.edu/urn-3:HUL.InstRepos:dash.current.terms-of-use\#LAA

\section{Share Your Story}

The Harvard community has made this article openly available.

Please share how this access benefits you. Submit a story.

\section{Accessibility}


DATE: 15 January 2019

NAME: Christina Liu, BA

TITLE: Ideal Length of Thread Forms for Screws Used in Screw Fixation of Nondisplaced Femoral Neck Fractures

\section{MENTOR:}

Michael J. Weaver, MD FACS

Appointment(s): Chief, Orthopaedic Trauma; Associate Professor, Harvard Medical School

Affiliation: Department of Orthopaedic Surgery, Brigham and Women's Hospital

Email: mjweaver@partners.org

\section{COLLABORATORS:}

Arvind Von Keudell, MD (AvK)

Appointments(s): Associate Professor, Harvard Medical School

Affiliation: Department of Orthopaedic Surgery, Brigham and Women's Hospital

Email: avonkeudell@mgh.harvard.edu

Michael McTague, MPH (MM)

Appointment(s): Senior Project Manager

Affiliation: Department of Orthopaedic Surgery, Brigham and Women's Hospital

Email:mmctague@bwh.harvard.edu

Kenneth Rodriguez, MD PhD (KR)

Appointment(s): Vice Chair of Clinical Services in Orthopaedics; Assistant Professor, Harvard Medical School

Affiliation: Department of Orthopedic Surgery, Beth Israel Deaconess Medical Center Email: ekrodrig@bidmc.harvard.edu 


\section{ABSTRACT \\ TITLE: Ideal Length of Thread Forms for Screws Used in Screw Fixation of Nondisplaced Femoral Neck Fractures}

Christina Liu BA, Arvind Von Keudell MD, Michael McTague MPH, Kenneth Rodriguez MD PhD, Michael J. Weaver MD FACS

PURPOSE: The purpose of this study is to determine the thread length that will maximize purchase within the femoral head while minimizing risk of crossing the fracture line. Additional analysis was conducted to identify factors associated with the maximal possible length of treads in minimally and non-displaced femoral neck fractures.

METHODS: We performed a retrospective study of all patients treated for a minimally or nondisplaced femoral neck fracture from April 1, 2004 through December 31, 2017. Only patients who had received a pre-operative CT or MRI scan were included. Fixation was then templated using radiographs and the distance from the subchondral bone to the fracture line was then measured.

RESULTS: The study included 127 patients. The average estimated length of lag screw threads was $33.2 \pm 6.67 \mathrm{~mm}$, with lower quartile of $29.1 \mathrm{~mm}$ and higher quartile of $37.2 \mathrm{~mm}$. The median was $32.0 \mathrm{~mm}$ and most frequently encountered estimate was $29 \mathrm{~mm}$. Estimated lag screw size did not differ significantly based on age or BMI, but both height $(\mathrm{p}<0.001)$ and race $(0.04)$ were positively correlated with estimated lag screw size and males had longer measurements compared to females, $37.2 \pm 7.0 \mathrm{~mm}$ vs $31.4 \pm 5.7 \mathrm{~mm}(\mathrm{p}<0.001)$, respectively.

CONCLUSION: In conclusion, we propose an additional lag screw thread form with length $26.0 \mathrm{~mm}$ to capture $90 \%$ of femoral neck fractures. 


\section{TABLE OF CONTENTS}

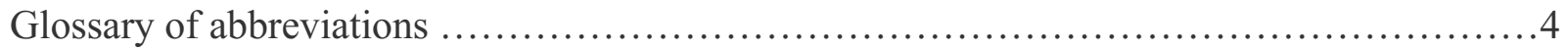

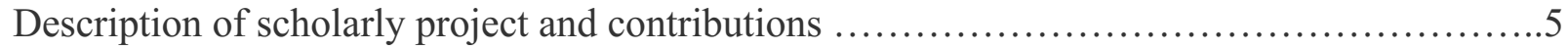

Appendix (complete draft of manuscript, references, list of tables, list of figures) .............6 


\section{GLOSSARY OF ABBREVIATIONS}

ACS: American College of Surgeons

AVN: avascular necrosis

BMI: body mass index

CT: computerized tomography

MRI: magnetic resonance imaging

RCT: randomized controlled trial

XR: x-ray radiography 


\section{STATEMENT OF SCHOLARLY PROJECT QUESTION AND CONTRIBUTIONS}

Hip fractures are commonly seen in the United States and it is frequently treated by internal fixation with cannulated lag screws, especially in those under 60 or have good bone health. Most major manufactures offer two standard thread lengths for cannulated lag screws, but oftentimes the longer thread length is too long and will cross fracture lines, thus losing the compressive force across the fracture.

The purpose of this project was to determine the thread length(s) of lag screws that will maximize purchase within the femoral head while minimizing risk of crossing the fracture line. Additional analysis was conducted to identify factors associated with the maximal possible length of threads in minimally and non-displaced femoral neck fractures.

As first author, I helped design the project, applied for IRB approval, collected all data, performed all statistical analysis with support from Harvard Catalyst, and drafted the manuscript. The statisticians at Harvard Catalyst conducted linear regression analysis using SPSS.

Manuscript has been submitted to Injury. Contributors helped with patient and case identification for inclusion in project. 


\section{INTRODUCTION}

In 2008 there were almost 341,000 emergency department visits in the United States for hip fractures ${ }^{1}$. That number is projected to surpass 500,000 annually by $2040^{2}$. The majority of hip fractures are femoral neck fractures that occur in elderly patients as a result of low-energy trauma ${ }^{3}$.

Cannulated screws are the most commonly used implant for internal fixation of femoral neck fractures ${ }^{4}$, especially in those under 60 or have good bone health ${ }^{5}$, given the quick recovery, short operative time, and low blood loss ${ }^{6,7}$. Most major manufactures offer two standard thread lengths listed in Table 1. To optimize purchase within the bone and improve compression across the fracture plane it is important to maximize the amount of screw threads within the femoral head fragment ${ }^{8,9}$. However, to achieve optimal compression between the fracture fragments, it is important for all the tread-forms to be across the fracture site ${ }^{10}$. Though a longer thread form has a higher risk of crossing fracture lines, the greater thread area also offers greater compression across fractures as shown in cadaveric femoral heads ${ }^{11}$. While a recent RCT showed no significant difference in outcomes between the $16 \mathrm{~mm}$ and the $32 \mathrm{~mm}$ screw in terms of nonunion, AVN, or re-operation it was underpowered to detect a subtle difference between implants ${ }^{12}$. There is no study to our knowledge that describes the ideal length of thread-forms for cannulated screws in the fixation of femoral neck fractures.

The primary aim of this study is to identify the thread length that will maximize purchase within the bone while minimizing risk of the tread-forms from crossing the fracture line in minimally and non-displaced femoral neck fractures. The secondary goal of this study was to identify factors associated with the maximal possible length of treads in minimally and nondisplaced femoral neck fractures.

The study was approved by the Brigham and Women's Hospital Institutional Review Board (Protocol 2018P000705). 


\section{PATIENTS AND METHODS}

\subsection{Study Design}

We performed a retrospective study of all patients treated at two ACS level 1 trauma centers between April 1, 2004 and December 31, 2017.

\subsection{Study Participants}

Cases were identified retrospectively by querying the hospital database for patients with femoral neck fracture who received pre-operative computerized tomography (CT) or magnetic resonance imaging (MRI). Inclusion criteria for the study were as follows: (1) Pre-operative CT or MRI imaging and (2) femoral neck fractures. Exclusion criteria were: (1) severely displaced or angulated fracture; (2) pathologic fracture secondary to malignancy or infection; (3) periprosthetic fractures; (4) poor imaging documented on final radiology report; and (5) no coronal reformatted images. Baseline characteristics for patient (age, gender, race, height, body mass index (BMI), and mechanism of injury) were recorded. A total of 127 patients met the inclusion criteria and were included in the study (Figure 1).

\subsection{Imaging and Measurements}

The pre-operative CT and MRI images were reviewed in a standard fashion. Mid-coronal slices of reformatted coronal CT and MRI sequences were used. Fracture lines were identified in the region of the femoral neck and possible trajectories for cannulated lag screws were templated. These trajectories were made to mimic screw paths of an inverted triangle configuration, with screws perpendicular to fracture plane and parallel to femoral neck axis. Care was taken to identify the lesser trochanter to ensure an appropriate simulated start-point for the planned screw trajectory. The distance between the subchondral bone and the fracture line was then measured along both the superior and inferior screw trajectory so that each patient had two screw measurements as seen in Figure 2. This distance from proximal femoral head to fracture line reflected the maximum possible thread-form length on the lag screw without penetrating into the joint or crossing the fracture line. One person performed all radiographic measurements for this study to minimize inter-reader variability. However, inter-reader reliability was performed with 10 randomly selected patients, demonstrating similar estimates.

\subsection{Variables}

Patient demographics, medical histories, and imaging were abstracted from the electronic medical record. Femoral head and neck fragment lengths were defined in millimeters. 


\subsection{Statistical Analysis}

Categorical variables were compared using a chi square test or Fisher's exact test. Continuous variables, including predicted thread-form length, were analyzed using a Student's t-test (ANOVA). Mann Whitney U test was performed for comparing medians of simulated superior and inferior screw estimates. For all tests, an alpha level less than 0.05 was considered statistically significant. Cases with missing data point(s) were excluded from the analysis for that variable and noted in the data table.

\section{RESULTS}

Of the 242 patients identified from a review of the hospital databases during the study period, 127 patients met the study inclusion criteria (Figure 1). Of these, 56 patients received preoperative $\mathrm{CT}$ imaging while the remaining 71 patients received MRI. Demographic and injury data is presented in Table 2 .

The average length of the maximal possible screw thread forms, as measured by distance from sub-chondral bone to fracture along the superior and inferior simulated screw trajectories, was $33.2 \pm 6.67 \mathrm{~mm}$. Based on our measurements, $90 \%$ of cases had estimated thread lengths greater than $26.0 \mathrm{~mm}$ while $95 \%$ of cases had estimates greater than $24.0 \mathrm{~mm}$. Figure 3 shows the distribution of estimated thread lengths with the lower quartile at $29.1 \mathrm{~mm}$ and upper quartile at $37.2 \mathrm{~mm}$. The interquartile range was $8.1 \mathrm{~mm}$ with a median of $32.0 \mathrm{~mm}$. Comparison of the simulated superior versus inferior screw trajectories showed a statistically significant difference with relative medians of $31.6 \mathrm{~mm}$ and $33.0 \mathrm{~mm}$ respectively $(\mathrm{p}=0.02)$.

Concerning secondary outcomes, table 3 presents the distribution of lag screw thread form lengths based on various factors such as age, gender, race, height, and BMI. The estimated lengths of thread forms were significantly longer in males (mean $37.2 \pm 7.0$ ) compared to females (mean $31.4 \pm 5.7, \mathrm{p}<0.001)$ and in patients identifying as Hispanic $(39.1 \pm 9.8, \mathrm{p}=0.04)$ compared to other races. Height was also positively correlated with longer estimated thread form lengths ( $\mathrm{p}<0.001)$. The estimated lengths of lag screw thread forms was not associated with age $(\mathrm{p}=0.65)$ or $\mathrm{BMI}(\mathrm{p}=0.32)$. Linear regression analysis showed that only height was significantly correlated with thread form length $(\mathrm{p}=0.002)$. 


\section{DISCUSSION}

Presently, most lag screws are manufactured with two standard thread form lengths, $16 \mathrm{~mm}$ and $32 \mathrm{~mm}^{12}$ (Table 1). Based on our data, the commonly available tread-form lengths do not appear to optimally treat non-displaced and minimally-displaced femoral neck fractures. While the $32 \mathrm{~mm}$ length may be used safely in approximately $50 \%$ of cases, the $16 \mathrm{~mm}$ tread is likely too conservative. A tread form length of $26 \mathrm{~mm}$ would improve screw purchase considerably and would still not cross the fracture line in over $90 \%$ of patients. In addition to analyzing the distribution of possible thread form lengths, our study also showed that increased height is associated with longer possible tread lengths. This is most likely due to the correlation between height and bone size ${ }^{13,14}$.

Based on previous biomechanical studies, stability of fracture fixation is determined largely by compression across fracture surface to transfer load sharing ${ }^{9}$. A larger thread area offers greater purchase, and thus increases compression across facture plane ${ }^{8}$. As such, for lag screws to offer the maximum purchase within the bone and compression across the fracture line, the thread form lengths should be equal to the distance from the sub-chondral bone of the femoral head to fracture line.

A recent study showed a failure rate of fixation of minimally displaced and non-displaced fractures to be $19 \%$, of which over $40 \%$ were due to loss of fixation ${ }^{15}$. Our results suggest that a longer thread length of $26 \mathrm{~mm}$ may offer better purchase within bone and thus lower this complication rate. Although a RCT from 2009 showed no significant difference in failure rates between patients treated with $16 \mathrm{~mm}$ versus $32 \mathrm{~mm}^{12}$, sample size calculations suggested over 3000 subjects were needed in each arm to detect subtle differences between groups. Further, patients in this RCT were randomized without consideration of femoral head to fracture line distances. It is unclear how many patients randomized to the longer lag screw had thread forms straddling fracture lines, which may also explain the lack of difference between the two groups. Our study suggests that half of patients with minimally and non-displaced femoral neck fractures have estimated femoral head to fracture line distances of less than $32 \mathrm{~mm}$ and thus poor candidates for the $32 \mathrm{~mm}$ lag screw. Depending on which manufacturer and cannulated screw set used, it may be that only the $16 \mathrm{~mm}$ tread lengths are available for this patient population. Either adding tread length options or increasing the minimum tread length would increase the screw 
purchase possible within the femoral head without compromising lag screw technique by crossing the fracture line.

A recent study utilized fully threaded screws to purposefully cross fracture lines during fixation of femoral neck fractures in an attempt to minimize shortening of the femoral neck without compromising fracture healing or screw pull-out ${ }^{16}$. Although this may bring into question the significance of not crossing the fracture line when using lag screws for screw fixation of femoral neck fractures, however, the majority of patients treated using this fully threaded screw method (18 of 24) were initially fixed and aligned with traditional lag screw technique, suggesting that it is still important to respect the fracture line in the initial fixation stage $^{16}$.

Our study has a number of limitations. It was based only on patients with CT or MRI scans available, regardless of method used in clinical care. CT and MRI were chosen as the imaging modality of choice for their high resolution, which allowed accurate determination of fracture angulation and displacement, as well as accurate radiographic measurements of theoretical thread length. Based on radiology reports, patients received CT or MRI either due to inadequate visualization of femoral neck fracture on initial hip XR or for concomitant abdominal or pelvic pathology. Only patients with minimally angulated and displaced fractures were included to ensure accurate simulated screw paths on radiographic imaging, and to reflect clinical practice as most patients who receive screw fixation have minimally displaced femoral neck fractures. It is possible that this population of patients is in some way different from the typical hip fracture patient. Additionally, our measurements were based on simulated screw trajectories, and there could be some difference between the measurements made and the clinical practice of placing screws. The results of this study demonstrate the need for additional prospective clinical studies measuring maximum thread form length in real time of patients presenting with minimally displaced femoral neck fractures.

\section{CONCLUSION}

In conclusion, it appears that the current thread-length options available are not ideal for the fixation of minimally displaced and minimally angulated femoral neck fractures. Given the common occurrence of these injuries, fracture implants should be designed to optimize purchase within the bone while maintaining the lag screw function of the implants. The addition of a 
$26 \mathrm{~mm}$ thread length screw would substantially increase the surface area of the treads making contact within the cancellous bone of the femoral head without crossing the fracture line in the vast majority of patients.

\section{REFERENCES}

1. Kim S, Meehan J, Blumenfeld T SR. Hip Fractures in the United States: 2008 Nationwide Emergency Department Sample. Arthritis Care Res (Hoboken). 2012;64(5):751-757.

2. Cummings SR, Rubin SM B. The future of hip fractures in the United States. Numbers, costs, and potential effects of postmenopausal estrogen. Clin Orthop Relat Res. 1990;252:163-166.

3. Antapur P, Mahomed N GR. Fractures in the elderly: when is hip replacement a necessity? Clin Interv Aging. 2011;6:1-7.

4. Ye Y, Hao J, Mauffrey C, Hammerberg M, Stahel P HD. Optimizing Stability in Femoral Neck Fracture Fixation. Ortho. 2015;38(10):625-630.

5. Rogmark C, Carlsson A, Johnell O SI. A prospective randomised trial of internal fixation versus arthroplasty for displaced fractures of the neck of the femur. Functional outcome for 450 patients at two years. J Bone Jt Surg Br. 2002;84(2):183-188.

6. Ravikumar KJ MG. Internal fixation versus hemiarthroplasty versus total hip arthroplasty for displaced subcaptial fractures of the femur - 13 year results of a prospective randomized study. Injury. 2000;31:793-797.

7. Bhandari M, Devereaux PJ, Swiontkowski MF, Tornetta P 3rd, Obremskey W, Koval KJ, Nork S, Sprague S, Schemitsch EH GG. Internal Fixation compared with arthroplasty for displaced fractures of the femoral neck. A meta-analysis. J Bone Jt Surg Am. 2003;85A(9):1673-1681.

8. Swiontkowski MF, Harrington RM, Keller TS VP. Torsion and Bending Analysis of Internal Fixation Techniques for Femoral Neck Fractures: the Role of Implant Design and Bone Density. J Ortho Res. 1987;5:433-444.

9. Stankewich, CJ, Chapman J, Muthusamy, R, Quaid, G, Schemitsch, E, Tencer, AF, Ching R. Relationship of Mechanical Factors to the Strength of Proximal Femur Fractures Fixed with Cancellous Screws. J Ortho Trauma. 1996;10(4):248-.

10. Uhl R. The Biomechanics of Screws. Orthop Rev. 1989;18(2): 130. 
11. Frandsen PA, Christoffersen H MT. Holding power of different screws in the femoral head: a study in human cadaver hips. Acta Orthop Scand. 1984;55:249-351.

12. Parker M AS. Short versus long thread cannulated cancellous screws for intracapsular hip fractures: A randomised trial of 432 patients. Injury. 2010;41:382-384.

13. Ruff CB, Trinkaus E, Walker A, Larsen CS. Postcranial robusticity in Homo. I: Temporal trends and mechanical interpretation. Am J Phys Anthropol. 1993;91(1):21-53. doi:10.1002/ajpa.1330910103

14. Pan N. Length of Long Bones and Their Proportion To Body Height in Hindus. $J$ Anat. 1924;(58):374-378.

http://europepmc.org/backend/ptpmcrender.fcgi?accid=PMC1249729\&blobtype=pdf.

15. Fixation using Alternative Implants for the Treatment of Hip fractures (FAITH) Investigators. Fracture fixation in the operative management of hip fractures (FAITH): an international, multicentre, randomised controlled trial. Lancet. 2017;389(10078):15191527. doi:10.1016/S0140-6736(17)30066-1.Fracture

16. Yoram A. Weil, Feras Qawasmi, Meir Liebergall, Rami Mosheiff AK. Use of fully threaded cannulated screws decreases femoral neck shortening after fixation of femoral neck fractures. Arch Orthop Trauma Surg. 2018;138(5):p661-667. 


\section{Table 1}

Standard thread lengths for large cannulated screws $\geq 6.5 \mathrm{~mm}$

\begin{tabular}{ll}
\hline Major Manufacturer & Standard thread lengths $(\mathrm{mm})$ \\
\hline DePuy Synthes ${ }^{\circledR}$ Cannulated Screw System & $16 \mathrm{~mm}$ \\
Smith \& Nephew ${ }^{\circledR}$ Large Cannulated Screw System** & $32 \mathrm{~mm}$ \\
& $16 \mathrm{~mm}$ \\
& $22 \mathrm{~mm}$ \\
& $32 \mathrm{~mm}$ \\
Stryker ${ }^{\circledR}$ Asnis III Cannulated Screw System & $46 \mathrm{~mm}$ \\
& $20 \mathrm{~mm}$ \\
Zimmer Biomet ${ }^{\circledR}$ 6.5/8.0mm Cannulated Screw System & $40 \mathrm{~mm}$ \\
& $40 \mathrm{~mm}$ \\
Zimmer ${ }^{\circledR}$ Magna-FX Cannulated Screw Fixation & $16 \mathrm{~mm}$ \\
System & $32 \mathrm{~mm}$ \\
\hline **16 and 32 mm part of 7.0mm Cannulated Screw Set, 22 and $46 \mathrm{~mm}$ part of $6.5 \mathrm{~mm}$ and $8.0 \mathrm{~mm}$ \\
Cannulated Screw Sets
\end{tabular}




\section{Table 2}

Characteristics of patients with femoral neck fractures

$$
\text { Overall }
$$

$\mathrm{N}=127$

Median age, years (range)

$71.9(76.79)$

Gender, \%

Female

Male

$68.5 \%$

$31.5 \%$

Mean height, cm (SD)*

$164.9 \pm 11.02$

Mean BMI, $\mathrm{kg} / \mathrm{m}^{2}$ (SD)**

$24.5 \pm 5.82$

Mechanism of Injury, \%

Fall

$79.5 \%$

Trauma

$5.5 \%$

Atraumatic

$15.0 \%$

Lag screw thread form length, mm (SD) $\quad 33.2 \pm 6.67$

BMI, body mass index; SD, standard deviation

* 16 cases with no height listed in chart near time of injury

** 19 cases with no BMI listed in chart near time of injury 
Table 3

Lag screw thread form length

\begin{tabular}{|c|c|c|c|}
\hline & $\begin{array}{l}\text { Overall } \\
(\mathrm{n}=127)\end{array}$ & $\begin{array}{l}\text { Lag screw thread form } \\
\text { length }(\mathrm{mm} \pm \mathrm{SD})\end{array}$ & $\mathrm{P}$ value \\
\hline Age, years: & & & 0.65 \\
\hline$<55$ & $15.0 \%$ & $33.6 \pm 6.9$ & \\
\hline $55-64$ & $15.0 \%$ & $34.1 \pm 6.5$ & \\
\hline $65-74$ & $23.6 \%$ & $33.8 \pm 7.4$ & \\
\hline $75-84$ & $22.8 \%$ & $32.6 \pm 7.0$ & \\
\hline$>85$ & $23.6 \%$ & $32.5 \pm 5.3$ & \\
\hline Gender: & & & $<0.0001$ \\
\hline Female & $68.5 \%$ & $31.4 \pm 5.7$ & \\
\hline Male & $31.5 \%$ & $37.2 \pm 7.0$ & \\
\hline Race/ethnicity: & & & 0.04 \\
\hline White & $85.0 \%$ & $33.0 \pm 6.6$ & \\
\hline Black & $4.7 \%$ & $31.6 \pm 5.0$ & \\
\hline Hispanic & $3.1 \%$ & $39.1 \pm 9.8$ & \\
\hline Asian & $0.8 \%$ & $28.4 \pm 0.7$ & \\
\hline $\mathrm{N} / \mathrm{A}$ & $6.3 \%$ & $35.3 \pm 5.0$ & \\
\hline Height, cm: & & & $<0.0001$ \\
\hline$<150$ & $7.1 \%$ & $30.5 \pm 4.9$ & \\
\hline $150-159$ & $21.3 \%$ & $30.6 \pm 6.0$ & \\
\hline $160-169$ & $26.8 \%$ & $32.0 \pm 4.7$ & \\
\hline $170-179$ & $22.8 \%$ & $35.2 \pm 6.7$ & \\
\hline$>180$ & $9.4 \%$ & $39.4 \pm 5.8$ & \\
\hline $\mathrm{N} / \mathrm{A}$ & $12.6 \%$ & $33.7 \pm 8.4$ & \\
\hline BMI, $\mathrm{kg} / \mathrm{m}^{2}$ : & & & 0.32 \\
\hline$<18.5$ & $12.6 \%$ & $33.0 \pm 5.4$ & \\
\hline $18.5-24.9$ & $32.3 \%$ & $32.4 \pm 6.4$ & \\
\hline $25.0-29.9$ & $32.3 \%$ & $33.8 \pm 6.4$ & \\
\hline$>30.0$ & $7.9 \%$ & $32.0 \pm 3.8$ & \\
\hline $\mathrm{N} / \mathrm{A}$ & $15.0 \%$ & $34.8 \pm 9.1$ & \\
\hline Mechanism of Injury: & & & 0.002 \\
\hline Fall* & $79.5 \%$ & $32.9 \pm 6.6$ & \\
\hline Trauma & $5.5 \%$ & $39.3 \pm 7.9$ & \\
\hline Other** & $15.0 \%$ & $32.6 \pm 5.1$ & \\
\hline
\end{tabular}

BMI, body mass index; SD, standard deviation

*Fall: low impact injury, fall from standing

**Other: atraumatic, history of primary metabolic bone disorder, chronic steroid use 


\section{Figure 1}

Hospital database $\mathrm{N}=242$ :

All patients who were diagnosed with femoral neck fracture and received pre-operative imaging with CT or MRI at Brigham \& Women's Hospital and Massachusetts General Hospital from Apr 2004 - Dec 2017.

Excluded based on mechanism of injury $N=22$ : metastasis (20), periprosthetic (1), GWS (1)

$N=220$ : Patients with primary native femoral neck fractures

Excluded based on image quality $\mathrm{N}=$ 93: displaced fracture (79), no coronal reformat (13), poor image quality (1)

$\mathrm{N}=127:$ Patients with well visualized minimally displaced femoral neck fractures on CT or MRI coronal images 
Figure 2

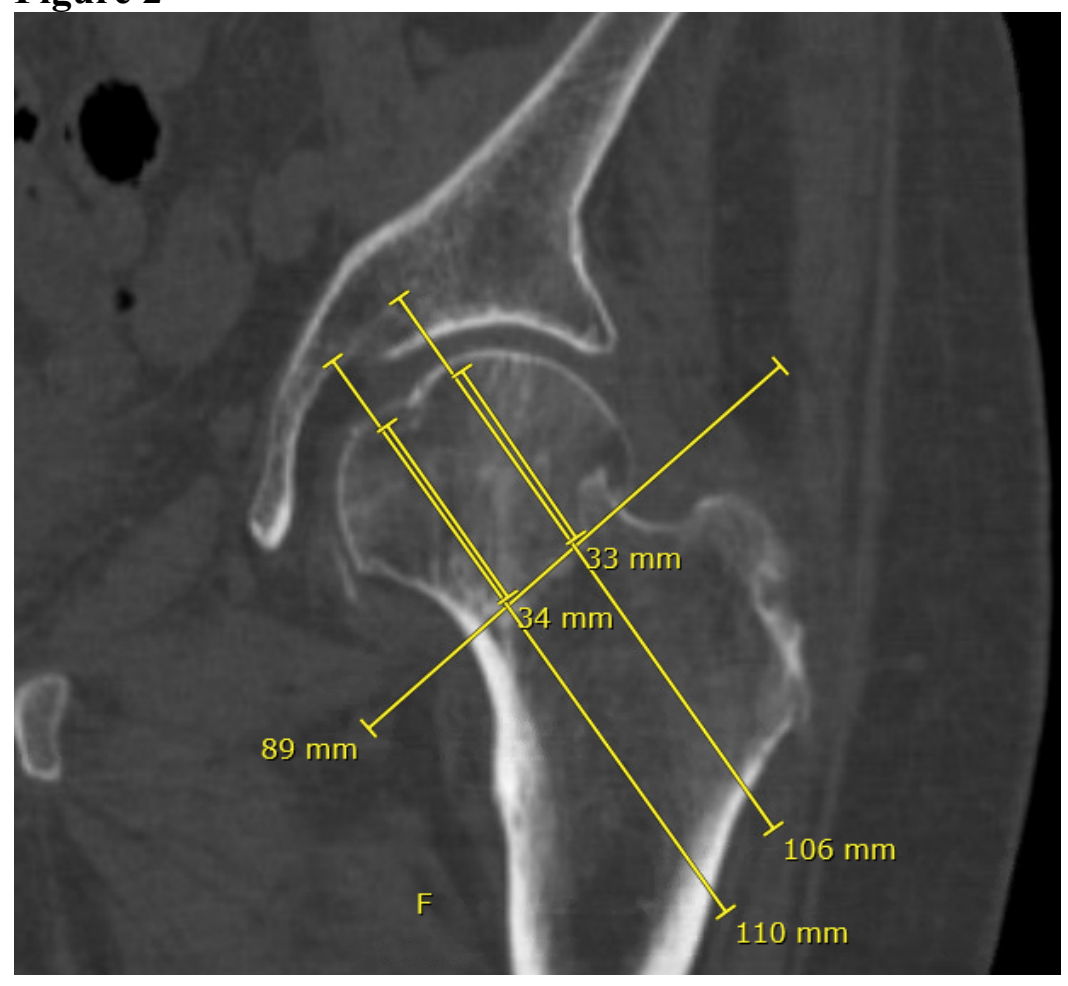


Figure 3
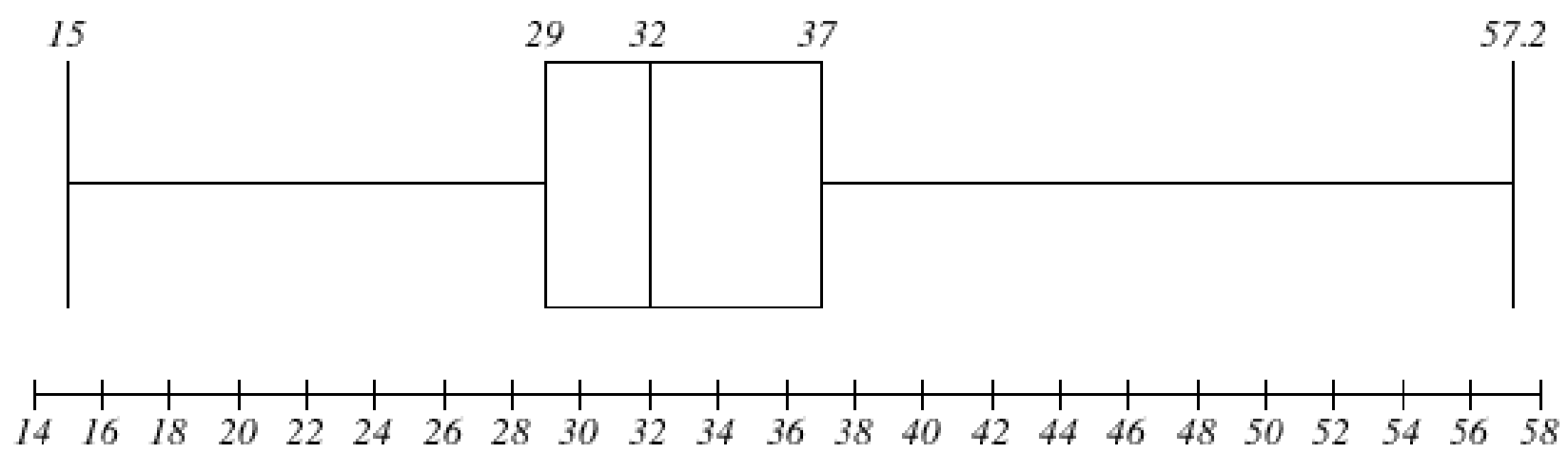

3A

\section{Length (mm)}

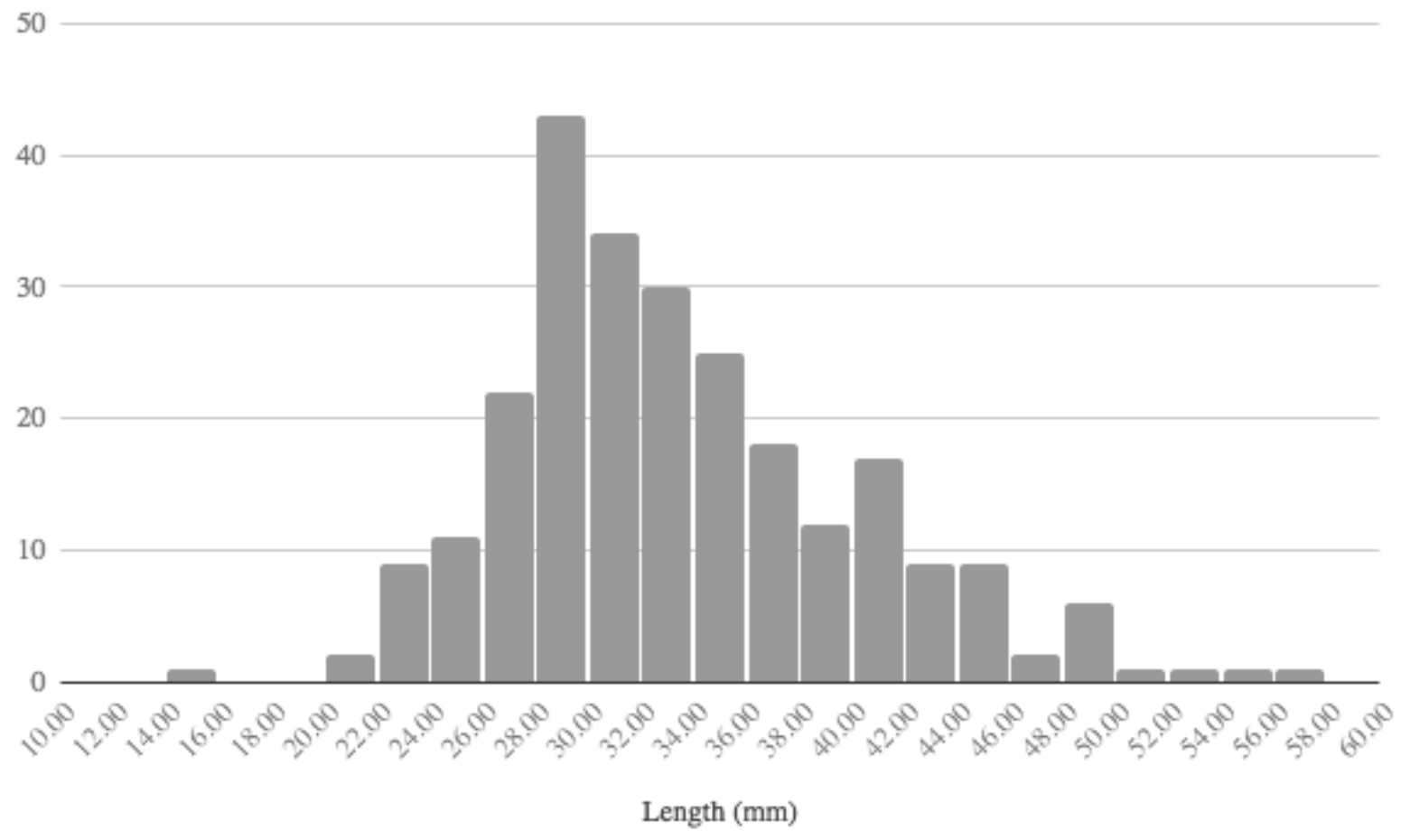

3B 